\title{
Editorial
}

Adelheid $\mathrm{Hu}^{\star}$ and Ingrid de Saint-Georges

\section{Multilingualism as a resource for learning - insights from a multidisciplinary research project}

https://doi.org/10.1515/eujal-2020-0012

\section{Globalisation, mobility and linguistic diversity}

Globalisation is a process full of complexities and inherent tensions. On the one hand, we are seeing increasing numbers of people from a variety of communities using a more diverse range of repertoires and entering into increasingly multilateral relationships. In this respect, globalisation is giving rise to more flexible and mixed views of identities, more hybrid language practices and new cultural scripts. But at the same time, perhaps as a response to these changes, we are witnessing the re-emergence of stronger nationalist and communitarian currents in many parts of the world.

Under this new globalised regime, neighbourhoods, workplaces, schools and universities are changing in Europe and beyond. For example, the number of children, young people and adults learning to use and navigate new languages at different points in their lives has surged. In education, mobile learners have also contributed to the diversification of classrooms, raising new questions as to how best to support them in their educational trajectories, in particular when their linguistic repertoires do not correspond with the languages of schooling. Simultaneously, issues related to fairness and equity have become more pressing in many spheres of social life.

\footnotetext{
*Corresponding author: Prof. Adelheid Hu, University of Luxembourg, Faculty of Humanities, Education and Social Sciences, E-Mail: adelheid.hu@uni.lu

Prof. Ingrid de Saint-Georges, University of Luxembourg, Faculty of Humanities, Education and Social Sciences, E-Mail: ingrid.desaintgeorges@uni.lu
} 


\section{Luxembourg as a case study}

The Grand Duchy of Luxembourg represents an especially rich case study when investigating the linguistic ramifications of globalisation. Luxembourg, situated between France, Belgium and Germany, has a long multilingual tradition. Since mediaeval times, several languages have been spoken on Luxembourgish territory, mainly different varieties of Luxembourgish (a West Germanic Moselle Franconian dialect), but also French and German, which used to be the two official languages of the country. In 1984, the authorities declared Luxembourgish to be the country's national language, and since then Luxembourgish, French and German have been the official languages of Luxembourg. The same complexity is found in the public education system, which is also trilingual. Luxembourgish is used mainly in preschool as the language for daily communication, German is used for literacy development in primary school, and French is used as the main language of instruction in secondary school. English is taught as an important foreign language in all schools.

At the same time, a very high number of migrants, expatriates and cross-border commuters live and/or work in Luxembourg. In this context, two types of multilingualism can be identified in the country. There is an "official" multilingualism including French, German and Luxembourgish. English is also increasingly used in administrative, work and school contexts. But this official multilingualism cohabits with the many other languages spoken within the super-diverse population. For school education, multilingualism is thus both the pervading context and the goal: the vast majority of students (including Luxembourgish students) learn and study in a second or third language (mostly German and French) and many of them reach a high degree of proficiency in at least four languages. There is also strong empirical evidence showing that migration-based multilingualism may lead to marginalisation and a higher probability of school failure (MENJE 2018; OECD 2019).

Beyond this, language(s) also play(s) an important role in the public discourse on Luxembourgish national identity. This discourse either stresses the importance of Luxembourgish as mother tongue or points to Luxembourg's multilingualism as the characterising feature of Luxembourgish identity. ${ }^{1}$ Although Luxembourg is in some regards specific and especially intricate from a linguistic standpoint, similar developments can also be observed in other countries and regions. This is certainly the case for border regions in general or officially bi- or

1 For more detailed information on the linguistic situation in Luxembourg, see e.g. Horner 2007; Horner and Weber 2008; Péporté et al. 2010; Weber and Horner 2012. 
trilingual places such as Belgium, Switzerland and South Tyrol. It also seems to be the case to some extent in the classrooms of many officially monolingual countries, which are finding themselves no longer populated by monolingual students but increasingly by multilingual learners with highly diverse language backgrounds, who learn their country's official language of schooling as well as English and other foreign languages.

\section{Challenges for research on multilingualism: a need for transdisciplinary approaches}

In view of the changing nature of classrooms in Luxembourg and beyond, research initiatives have multiplied, seeking to identify the best pedagogical and social responses to diversity on a new scale. Given the complexities of the topic of diversity, with its inherent personal, cognitive, emotional, political, societal and ideological dimensions, calls for inter-/transdisciplinary research in multilingualism have also been getting louder. In a recent contribution, the Douglas Fir Group (2016) explains and justifies such an interdisciplinary approach as follows:

\footnotetext{
... increasingly numerous and more diverse populations of adults and youth become multilingual and transcultural later in life, either by elective choice or by forced circumstances, or for a mixture of reasons. They must learn to negotiate complex demands and opportunities for varied, emergent competencies across their languages. Understanding such learning requires the integrative consideration of learners' mental and neurobiological processing, remembering and categorizing patterns, and moment-to-moment use of language in conjunction with a variety of socioemotional, sociocultural, sociopolitical, and ideological factors. (p. 19)
}

This special issue showcases one such interdisciplinary research initiative, the doctoral training unit Capitalizing on Linguistic Diversity in Education (CALIDIE).

The doctoral training unit, funded by the Luxembourg National Research Foundation (FNR) (Project ID PRIDE15/10921377/CALIDIE/HU), is composed of $10 \mathrm{PhD}$ students, 1 post-doctoral researcher and 11 senior experts from different disciplines. The programme started its work in January 2017 within the Faculty of Humanities, Education and Social Sciences at the University of Luxembourg. Since then, its members have organised activities such as regular conferences, retreats and seminars as well as an international and multidisciplinary lecture series. During these activities, the doctoral researchers, their supervisors and experts from other universities have had extensive opportunities to discuss individual $\mathrm{PhD}$ and post-doc projects as well as common overarching questions. Over 
time, CALIDIE has attracted other young researchers working on similar research questions, who regularly participate in the events organised.

The research conducted within CALIDIE focuses on various theoretical and empirical approaches to the study of multilingualism. More specifically, it addresses the question of how learners' linguistic repertoires interact with their learning. The researchers seek to investigate in particular how multilingualism - conceptualised as the interplay of multiple linguistic repertoires (mother tongue(s), language(s) of schooling, foreign languages, second languages) - affects learning practices and processes. They also consider how multilingualism can be capitalised on and transformed into a resource for educational success and social well-being. Finally, they attempt to identify factors that may prevent multilingualism from being a positive resource for learning and development. Bringing together psychologists, educationalists and linguists, the research group fully acknowledges the expertise within specific disciplinary areas but at the same time seeks to transcend disciplinary thinking to address a common thematic challenge.

In this regard, we can look back at an intensive learning process for all those involved in our research group, especially when it comes to understanding each other's disciplinary perspectives. Each discipline typically constructs knowledge in its own ways and is usually associated with different methodological procedures. For example, while psychometric studies usually examine variables in a way that is as context-independent as possible, ethnographic or anthropological approaches aim on the contrary to provide context-rich data through the analysis of case studies. The research scale also varies from one field to the next: in largescale quantitative studies, questionnaires will be sent to thousands of respondents, whereas in more qualitative or critical approaches, researchers will use in-situ observations or the close analysis of discursive moves from people's unique experiences to understand multilingual processes and practices. Finally, central concepts such as language, multilingualism and learning can mean different things in different disciplines. While language can be treated as one variable amongst others in a quantitative research setting, the concept in itself has been fundamentally questioned in recent qualitative, sociolinguistic studies (see e.g. Pennycook 2010).

Despite these different entry points, a clear consensus developed over the course of three years of the project as to the added value of engaging in an interdisciplinary dialogue. For example, CALIDIE participants felt that they had become more adept in articulating the unique value of their approach to others, but also in identifying the limits and blind spots of their own perspective. Everyone learned to present their work in terms that were intelligible to others. In the process they refined their methods of communicating their research to both internal 
and external disciplinary audiences. Finally, we witnessed an increased awareness of the societal purposes that might best be served by each approach.

\section{This special issue}

The special issue contains eight articles written by researchers in the CALIDIE group or associate members. The articles give a good impression of the themes and approaches investigated by the authors over the past few years.

The eight articles first study learning and multilingualism from a broad perspective, including formal education from early childcare to school and higher education. Two articles also focus on migration and its consequences for both educational success and identity construction. The articles are anchored in education, linguistics, psychology and the sociology of globalisation. This integrative approach offers a broad view of settings where learning happens and multilingualism is experienced.

The main topics dealt with include agency and individuals' semiotic resources, emotions and learning, translanguaging, institutional policies and their impact on learners. The texts also contain reflections on linguistic norms and prescriptions in highly diverse classrooms, power dynamics and language ideologies. The research thus navigates between different levels: individual cases (micro), institutions (meso), and finally ideological structures such as belief systems or political values (macro). Most papers relate to empirical research in Luxembourg, although two articles refer to other contexts in Germany (Stierwald) and Norway (Obojska).

The section below summarises the main points in each article.

\section{Special issue contributions}

In their article Young children as actors of institutional language policies and practices in day care centres. Insights from field research in plurilingual Luxembourg, Kevin Simoes and Sascha Neumann focus on multilingual education within the Luxembourgish context of early childhood education and care (ECEC). Within this context, issues of linguistic diversity and multilingual education have increasingly gained in importance. Based on ethnographic data collected in Luxembourgish, Simoes and Neumann concentrate especially on children's agency within Luxembourgish day care centers and explore how children contribute to the constitution of language practices in institutional day care centres with their particular language repertoires. Inspired by relational theories of agency, emphasis- 
ing the co-dependency between structure and agency, their findings demonstrate that the status of children as actors in institutional language practices is strongly connected to institutional policies. At the same time, the children also play a vital role in maintaining, undermining or altering these policies. The translanguaging practices of children and caregivers seem to be particularly crucial in bridging institutional language policies and individual language repertoires.

In the second article, Moving beyond language(s): a case study on a newcomer's translanguaging practices, Sarah Degano and Claudine Kirsch pay particular attention to the deployment of the semiotic repertoires of newcomers to Luxembourgish primary schools and their purposes for translanguaging. Closely observing the language practices of one 11-year-old boy of Cape Verdean and Portuguese origin, the authors particularly investigate the resources in the newcomer's semiotic repertoire. They also examine how the boy orchestrates his various resources to make meaning, and when he uses translanguaging. Adopting a socialsemiotic perspective and using ethnographic research methods (including participant observation, video-recorded activities, semi-structured interviews and stimulated recall interviews with teachers and pupils), Degano and Kirsch show how the boy activated his prior knowledge and deployed his resources in complex ways to engage in learning activities, construct knowledge, communicate thoughts and manage his emotions. He was able to make sense of the curricular content despite the language barriers he encountered.

Mona Stierwald's text Bi-plurilingual formulation practices in conversational writing interactions leads us to a different educational context: a university research seminar in Romance studies at the Goethe University Frankfurt. Investigating university students' plurilingual academic literacy practices, Stierwald concentrates on a specific writing activity: conversational writing interaction - a format where two or more co-authors discuss and write a text together. Stierwald pursues two main aims: creating a preliminary typology of repair operations occurring during the writing process, and observing the actual use (or non-use) of plurilingual resources when students employ oral formulation procedures. Adopting a conversation analytic approach, she presents a detailed sequential analysis of three moments of interaction. Based on this analysis, Stierwald shows that there is a functional distribution between German and French (German for organisation and metalinguistic comments, French to formulate utterances). Concerning students' uses of plurilingual repertoires, interestingly they cannot be observed; the students exclusively use either the dominant language of the course (German) or the target language of the discipline or the writing task (French). For Stierwald the reasons might be pragmatic and strategic: integrating more languages into the interactional writing process might require more time and effort since the interlocutors would have to negotiate additional (metalinguistic) issues. 
Ingrid de Saint-Georges, Gabriele Budach and Constanze Tress also deal with the university context in their contribution: "We need to become 'educational chameleons"': from unified to multiple norms in a multilingual and international higher education context. They do not concentrate on a predominantly bilingual setting as Mona Stierwald does. The article sheds light instead on the learning experience of students on a trilingual Master programme where multiple linguistic, cultural and academic norms interact. Questioning current benchmarking and standardising discourses, the paper asks how students cope when they are asked to respond to diverse norms and what they learn from being exposed to more than one predominant standard. To answer this question, de Saint-Georges, Budach and Tress draw on semi-structured qualitative interviews originally conducted by students for a class project. The data shows that dealing with multiple norms can appear messy and challenging at first glance, but students nevertheless claim to thrive if specific support is provided, e.g. if they can use different repertoires for classes and assignments, if they feel that teaching staff value their background or if they can benefit from a flexible multilingual approach. The experiences discussed lead de Saint-Georges, Budach and Tress to stress that more open debates about norms and scripts of evaluation are important in light of the new globalised classroom.

Stephanie Hofmann's article Multilingualism and internationalisation in doctoral education: Discourse, positioning and agency also deals with higher education, but focuses on the specific area of doctoral education. Using a discourse analytic approach, Hofmann investigates in particular how doctoral researchers position themselves within powerful macro-level discourses about internationalisation, language and academic success. Hofmann also focuses on how the students perceive their own agency and sense of self within this complex lingua-cultural and socio-economic nexus. With two case studies relating to the experiences of international $\mathrm{PhD}$ researchers at the University of Luxembourg, Hofmann demonstrates how they construct themselves as plurilingual subjects and sheds light on their struggles, values, beliefs and wishes. The data shows the tension between multilingualism (associated with the "local") and English (associated with the "international"). For Hofmann, although the University of Luxembourg seems to offer an excellent context for researching and writing multilingually, this context does not automatically lead to multilingual practices within doctoral research. Her analysis reveals how the (perceived) prevalence of English and the pressure to publish in international journals mean that $\mathrm{PhD}$ researchers struggle to use their full linguistic repertoires when writing their thesis.

The article by E'Louise Botes, Jean-Marc De Waele and Samuel Greiff, The power to improve: Effects of multilingualism and perceived proficiency on enjoyment and anxiety in foreign language learning, moves the focus to young adults 
from across the world engaged in learning a new foreign language. Building on positive psychology and studies in language acquisition that investigate how emotions interact with language learning, the authors analyse responses to an online questionnaire. The questionnaire asks learners to self-report on the languages they know, to state how proficient they feel and to indicate their perceived level of enjoyment or anxiety associated with foreign language learning. Botes, De Waele and Greiff concentrate on the relationship between being highly multilingual and feeling highly confident about one's skills on the one hand, and experiencing feelings of enjoyment or anxiety on the other. The authors show a small but statistically significant effect among these variables: while knowing multiple languages and feeling confident about one's proficiency leads to less anxiety in learning yet another new language, these conditions do not automatically stimulate more enjoyment, raising the question of how pedagogical practices can enhance enjoyment. The paper provides a unique window onto the complex links between multilingualism, self-perceived foreign language proficiency, and enjoyment/anxiety.

The final two texts adopt a critical perspective on broader societal discourses related to migration, integration and foreignness. They also discuss strategies migrants use when confronted with discriminatory practices.

Bernardo Tavares's chapter Compounding forms of inequality: Cape Verdean migrants' struggles in education and beyond in Luxembourg is a call to address the social inequalities perceptible at the nexus of race, ethnicity, gender and language. Working from a critical ethnographic sociolinguistic perspective, Tavares retraces the educational trajectories and subsequent life and work opportunities of three speakers with migratory backgrounds from Cape Verde who experienced the complex linguistic regime of Luxembourg's education system. By analysing open-ended interviews, he looks at the role that languages, and German in particular, played in the life trajectory of the participants observed. Each case study portrays migrants who have been successful, but each portrait also pinpoints occasions where language skills significantly altered and limited their educational trajectory and upward mobility. The analysis also clarifies which factors contributed to the most successful outcomes, such as the interviewees' particularly resilient personalities or their chance encounters with teachers or administrators who acted as advocates for them. This study contributes to the sociolinguistics of globalisation and the anthropology of mobility. It vividly highlights the fragility of migrant children and migrant learners in education systems, where the stigmas of migratory backgrounds, race and ethnicity compound linguistic struggles.

Finally, Maria Obojska's article What's in a name? Identity, indexicality and name change in an immigrant context explores a strategy sometimes adopted by migrants in a bid to disalign with identities and linguistic resources that are less 
valued in the host society - changing their name. Analysing how one member of a transnational Polish family in Norway narrates this name change, Obojska proposes a narrative that informs us about the complex identity negotiations migrants are often required to navigate to try to fit in and benefit from symbolic and economic capital similar to the capital enjoyed by members of the dominant majority. Through a detailed analysis of indexicality, stances, participant roles and micro-/macro-discursive identity constructions, the reader discovers how for migrants, the identity positions available are intertwined with other factors (e.g. educational and work trajectories and group portrayal in public discourse). For the interviewee in Obojska's paper, changing his name was an opportunity to dissociate from negative discourses about Poles circulating in social spaces, to react to previous bullying in schools and to claim a more powerful identity. Telling his story to a researcher was also a way of putting his new identity on record. The proposed identity is not the disempowered, bullied, marginal migrant identity or the assimilated Norwegian identity, but a mixed Polish/Norwegian status in between the two.

\section{Insights from a transdisciplinary perspective}

Each individual text has its own specific aim, context, perspective and methodological approach. Each article also attempts in its own way to meet the original challenge: to improve our understanding of the links and interaction between multilingualism and learning in education from an interdisciplinary perspective. But it is also important to ask what we can learn from these eight different enquiries taken together. What do they teach us about our original questions? What new questions emerge from joint research on a common theme? Is it scientifically and epistemologically legitimate to relate outcomes from a such a wide range of studies, including a large-scale study in psychology, an ethnographic study in a primary school, a conversation analytic study of writing interactions and a discourse analysis of a name change narrative? To what extent is it possible to relate findings from one geographical or cultural area to another (e.g. is it possible to compare Polish migrants in Norway (Obojska) and Cape Verdean migrants in Luxembourg (Tavares))? Although we are aware of potential tensions and incompatibilities between various epistemological and cultural stances, it nevertheless seems essential, with all due caution, to outline some insights gained from reading the eight texts, in particular with regard to our initial research questions:

- How do learners' linguistic repertoires interact with their learning, and how does multilingualism affect learning practices and processes? 
- What factors encourage multilingualism as a positive resource for learning and development, or prevent it from serving this function?

\subsection{Linguistic practices, learning strategies and the social world}

Even if the focus lies on individuals and their practices, one point that clearly stands out in all the contributions is that individual learning practices and the use of multilingual repertoires for learning processes occur in constant negotiation and conjunction within the surrounding social world. The extent to which children, adolescents or adults build positive multilingual identities and develop self-confidence and agency largely depends on the way in which their social world encourages or discourages them to do so (Hu 2020). In this regard, language policies in educational institutions, for example, can have a strong impact on individual learners and the way in which they use their plurilingual repertoire. For example, whether an educational environment has a monolingual habitus or a "target-language" orientation (e.g. Stierwald), or whether it values inclusive multilingualism and multiple norms (e.g. de Saint-Georges, Budach \& Tress), will create different possibilities for learners to learn content and display what they know. Educational policies themselves are also part of broader public discourses that affect learning opportunities: how learners' identities are positioned in the public and media discourses (e.g. Tavares), the (perceived) global pressure to be proficient in one language or another (e.g. Hofmann), and the way in which ethnicities are valued in society (e.g. Obojska, Tavares) will often affect learning, even down to the level of classroom exchanges between peers or between learners and teachers.

\subsection{Emotions, agency, identity}

The articles further highlight the existence of intricate interactions between emotions (positive or negative), learning and multilingualism. For example, one of the findings is that, in the most positive situations, where learners already know multiple languages and are feeling confident in their learning abilities, they show less anxiety associated with learning a new language or new content. On the contrary, knowing few languages, or knowing many languages but not feeling confident with regard to one's language skills, seems to have adverse effects on learning (e.g. Botes, De Waele and Greiff; Tavares).

In addition, different conditions seem to nurture both positive and negative emotions with regard to (language) learning. For example, if learners are able to 
use a multiplicity of repertoires, if efforts to meet norms are recognised, if time to adapt is given, if people display strong feelings of agency or resilience, or if they are able to construct positive identities about themselves, well-being and learning seem to increase (de Saint Georges, Budach and Tress; Degano and Kirsch). On the contrary, if teachers, learning contexts or institutions do not support the learner, confidence and resilience are eroded. For example, if teachers or peers stigmatise learners and their linguistic repertoires, this has an impact on their learning trajectory (Tavares; Obojska). Likewise, if learners belong to a group that is misrepresented in public discourse, or if there is a narrow focus in class on their linguistic abilities to the detriment of other abilities, then positive emotions, identities and agencies for learning are also undermined (Degano \& Kirsch). In that sense, it is interesting to note that - at least in the cases described here - the youngest learners are perhaps the most able to challenge language policies. In the preschool context, caregivers are often forced to adjust their practices to children's needs (Simoes and Neumann). At higher levels of education questioning norms often seems to be more difficult and the ability to play with them flexibly is less apparent (Hofmann; Stierwald). We can relate this finding to another question and ask whether multilingual pedagogies are perhaps more developed and accepted in (early) childhood and primary contexts but less so in secondary schools or universities.

\subsection{Institutional policies, norms and assessment}

Another point that comes to the fore through the various articles, especially in Degano and Kirsch, Stierwald, Hofmann, and Tavares, is the ways in which normalised practices interact with successful learning. Having the expected accent or the right combination of languages, writing and speaking without making mistakes and understanding expectations in assessment are all part of what institutions like schools or workplaces anticipate, across different geographical and cultural contexts. Social and linguistic norms by themselves make life somewhat predictable. They facilitate orientation, judgements and interactions that would be made more difficult without them. What constitutes a challenge, however, is when normalised practices tied to one group or field become heralded as universal, when they go unquestioned, meaning that as a result, individuals who cannot meet the linguistic norms and dominant practices are labelled as failures or subaltern community members. Several authors (e.g. Canagarajah 2006) propose that other, more open views of normalised practices are possible, notably views recognising that not all linguistic standards are useful in the same way across the board. For these authors, being able to navigate different practices is an asset for 
everyone, including members of dominant majorities who increasingly find themselves in more egalitarian interactions with speakers of other languages and with other cultural practices than those they were exposed to before. The articles (e.g. de Saint Georges, Budach and Tress; Hofmann; Tavares) suggest that more debates about linguistic and cultural norms could be valuable, including tougher conversations about the incommensurability of some norms with others and what happens to sociality when norms clash. The papers also point to the fact that learners who do not meet the expected practices are perhaps abiding by other norms that are valuable in other contexts and equally important to their lives and identities. One issue is thus how schools, policies and institutions can expand learners' repertoires for everyone and encourage everyone to reflect on, engage with and embrace different normative practices as opposed to a single standard.

\subsection{Linguistic flexibility, translanguaging and multimodality}

In several articles, the authors make a plea for more linguistic flexibility and acceptance of more translanguaging practices. For example, Simoes and Neumann suggest that translanguaging practices should be considered as one of the key starting points to create a plurilingual ecology in and through everyday practice in day care centres. Degano and Kirsch conclude that teachers can promote knowledge communication and construction by adopting flexible and interactive multilingual and multimodal semiotic practices that enable students to co-construct meaning, as well as assessment procedures that avoid monolinguality and monomodality. Even in Luxembourg, however, where multilingualism is part of everyday life, the ideology of language separation obviously remains very strong in the school context, and translanguaging is often thought of as a practice that should be avoided. Even officially multilingual (educational) settings still enforce a deeply monolingual habitus (Gogolin 2013), as some articles paradoxically show, suggesting that perhaps it is important to rethink how integrative multilingual learning practices, using all available linguistic resources for knowledge construction and understanding, could be implemented. Some articles seem to suggest that making room for mistakes, facilitating trial and error and allowing for different accents and less-than-perfect writing could be a stepping stone, even in preparing for more stringent norms. A more flexible approach would perhaps preserve the feelings of enjoyment, belonging and confidence that can encourage further learning.

In addition, the articles show that the weight given to written literacy in educational contexts does not do justice to what learners actually know. Several articles (Simoes and Neumann, Degano and Kirsch, Tavares) portrayed learners 
speaking multiple languages, highly adaptable to different contexts, able to follow courses and understand content but not to express what they had learned and knew in the form expected by the institution. When the authors focused on how learners displayed their learning in modes other than writing, it became clear that the learners had understood more than their written expression in the dominant school language would let them show. They had found their own strategies for participating, displaying that they belonged and showing their power of agency. Often, however, these skills passed under the radar if the learners were only assessed on their written capabilities and assessment was focused on the product of learning rather than the learning process.

\subsection{Migration, integration and discrimination}

Most texts in this special issue focus on specific educational institutions such as schools or universities. Nevertheless, it is clear that the specific practices used by individual institutions need to be related to broader societal belief systems, the perception of otherness, (national or ethnic) stereotyping and other ways of constructing differences between people. Deep-rooted values and beliefs, related for example to who belongs to an "in-group” or "out-group”, have an impact on learning. They play an important role in communication and interaction in educational institutions, for both teachers (Wagner and $\mathrm{Hu} 2020$ ) and pupils/students. The contributions by Tavares and Obojska show very clearly that experiences in early school life (such as bullying or other kinds of discrimination) are consequential and can affect self-confidence, in some cases through individuals' entire lives and professional careers. These articles show that it is important to clearly relate the analysis of language practices for a specific case in a specific context to broader societal levels. In other words, it is essential to relate local, individual practices not only to institutional policies but also to values in culture, politics, religion and economy at the macro level. The current revival of nationalistic thinking, the weight given to monolithic national identities and the competitiveness of late capitalist societies are all troublesome emerging patterns when analysing local and individual practices. Policy makers and other authorities in the educational arena across Europe have a responsibility to take these complexities into account.

Acknowledgment: This work was supported by the Luxembourg National Research Fund PRIDE15/10921377/CALIDIE/Hu. 


\section{Bibliography}

Canagarajah, A. Suresh. 2006. Changing Communicative needs, Revised Assessment Objectives: Testing English as an International Language. Language Assessment Quarterly 3(3). 229-242.

Douglas Fir Group. 2016. A Transdisciplinary Framework for SLA in a Multilingual World. The Modern Language Journal, 100 (Supplement 2016). 19-47.

Gogolin, Ingrid. 2013. The "monolingual habitus" as the common feature in teaching in the language of the majority in different countries. Perlinguam Journals, 38-49. http://perlin guam.journals.ac.za (accessed 3 April 2020).

Horner, Kristine. 2007. Language and Luxembourgish national identity: ideologies of hybridity and purity in the past and present. Berlin: Walter de Gruyter.

Horner, Kristine \& Jean-Jacques Weber. 2008. The Language Situation in Luxembourg. Current issues in language planning, 9(1). 69-128.

$\mathrm{Hu}$, Adelheid. 2020. In press. Building a plurilingual identity. In: Anat Stavans \& Ulrike Jessner (eds), The Cambridge Handbook of Child Multilingualism. Cambridge: Cambridge University Press.

MENJE. 2017. Les chiffres clés de l'Éducation nationale: statistiques et indicateurs 2015-2016 / The key figures of the national education: statistics and indicators 2015-2016. Luxembourg: Ministère de l'Éducation nationale, de l'Enfance et de la Jeunesse.

MENJE. 2018. Bildungsbericht Luxembourg 2018. Luxembourg: Ministère de l'Éducation nationale \& University of Luxembourg.

OECD. 2019. Programme for international student assessment (PISA) - Results from Pisa 2018. https://www.oecd.org/pisa/publications/PISA2018_CNT_LUX.pdf (accessed 31 july 2020)

Pennycook, Alastair. 2010. Language as a Local Practice. Routledge: London.

Péporté, Pit, Sonja Kmec, Benoît Majerus \& Michel Margue (2010). Inventing Luxembourg - Representations of the Past, Space and Language from the Nineteenth to the Twenty-First Century (Vol. 1). Leiden: Brill.

Wagner, Jean-Marc \& Adelheid Hu. 2020. Construction of difference and homogeneity: Teacher narratives about diversity in the Luxembourgish school system. European Journal for Applied Linguistics. 8(1). 1-26.

Weber, Jean-Jacques \& Kristine Horner. 2012. The trilingual Luxembourgish school system in historical perspective: progress or regress? Language, Culture and Curriculum, 25(1). 3-15. 